\title{
Long-term field test of solar PV power generation using one-axis 3-position sun tracker
}

\author{
B.J. Huang*, W.L. Ding, Y.C. Huang \\ New Energy Center, Department of Mechanical Engineering, National Taiwan University, Taipei, Taiwan
}

Received 20 November 2010; received in revised form 30 April 2011; accepted 1 May 2011

Available online 27 May 2011

Communicated by: Associate Editor Nicola Romeo

\begin{abstract}
The 1 axis-3 position (1A-3P) sun tracking PV was built and tested to measure the daily and long-term power generation of the solar PV system. A comparative test using a fixed PV and a 1A-3P tracking PV was carried out with two identical stand-alone solar-powered LED lighting systems. The field test in the particular days shows that the 1A-3P tracking PV can generate $35.8 \%$ more electricity than the fixed PV in a partly-cloudy weather with daily-total solar irradiation $H_{T}=11.7 \mathrm{MJ} / \mathrm{m}^{2}$ day, or $35.6 \%$ in clear weather with $H_{T}=18.5 \mathrm{MJ} / \mathrm{m}^{2}$ day. This indicates that the present $1 \mathrm{~A}-3 \mathrm{P}$ tracking PV can perform very close to a dual-axis continuous tracking PV (Kacira et al., 2004). The long-term outdoor test results have shown that the increase of daily power generation of 1A-3P tracking $\mathrm{PV}$ increases with increasing daily-total solar irradiation. The increase of monthly-total power generation for $1 \mathrm{~A}-3 \mathrm{P}$ sun tracking $\mathrm{PV}$ is between 18.5-28.0\%. The total power generation increase in the test period from March 1, 2010 to March 31, 2011, is 23.6\% in Taipei (an area of low solar energy resource). The long-term performance of the present $1 \mathrm{X}-3 \mathrm{P}$ tracking PV is shown very close to the 1-axis continuous tracking PV in Taiwan (Chang, 2009). If the 1A-3P tracking PV is used in the area of high solar energy resource with yearlyaverage $H_{T}>17 \mathrm{MJ} / \mathrm{m}^{2}$ day, the increase of total long-term power generation with respect to fixed PV will be higher than $37.5 \%$. This is very close to that of dual-axis continuous tracking PV.

The 1A-3P tracker can be easily mounted on the wall of a building. The cost of the whole tracker is about the same as the regular mounting cost of a conventional rooftop PV system. This means that there is no extra cost for 1A-3P PV mounted on buildings. The 1A-3P PV is quite suitable for building-integrated applications.
\end{abstract}

(C) 2011 Elsevier Ltd. All rights reserved.

Keywords: Sun tracking PV; One-axis sun tracker; Stand-alone solar PV system; Solar power generation

\section{Introduction}

The tracking flat PV system is one of the methods to increase the PV power generation. Neville (1978) has shown theoretically that in a mid latitude region $\left(30^{\circ}\right)$, the overall solar energy capture can increase about $41 \%$ using two-axis tracking, compared to a fixed PV module tilted at an angle equal to the local latitude. For a one-axis tracking system, the increase is $36 \%$. The increase of solar energy capture due to sun tracking is region by region depending on the local meteorological conditions. $\mathrm{Li}$

\footnotetext{
* Corresponding author.

E-mail address: bjhuang@seed.net.tw (B.J. Huang).
}

et al. (2010) theoretically investigated the optical performance of the inclined south-north single-axis tracking solar PV module through a mathematical procedure to estimate the annual collectible solar radiation on fixed and tracked PV modules. It was found that, compared to fixed south-facing solar PV modules inclined at an optimal tiltangle, the increase in the annual solar gain due to using one-axis sun tracking was above $30 \%$ in the areas with abundant solar resources and less than $20 \%$ in the areas with poor solar resources. The theoretical prediction of the increase of electrical generation of sun-tracking PV modules may be in large errors due to unpredictable factors, such as diffuse radiation, ground or obstacles reflection, wind speed/direction, and air dust and moisture 


\begin{tabular}{|c|c|c|c|}
\hline \multicolumn{4}{|c|}{ Nomenclature } \\
\hline$E_{\text {inc }}$ & $\begin{array}{l}\text { power generation increase of } 1 \mathrm{~A}-3 \mathrm{P} \text { PV (dimen- } \\
\text { sionless) }\end{array}$ & $I_{T}$ & $\begin{array}{l}\text { instantaneous solar irradiation on the fixed PV } \\
\text { tilt }\left(\mathrm{W} \mathrm{m}^{-2}\right)\end{array}$ \\
\hline$H_{T}$ & daily-total solar irradiation on the fixed PV tilt & $V$ & battery voltage $(\mathrm{V})$ \\
\hline & $\left(\mathrm{MJ} / \mathrm{m}^{-2}\right)$ & $\beta$ & stopping angle of $1 \mathrm{~A}-3 \mathrm{P}$ tracker in the morning \\
\hline$I$ & battery charging current (A) & & or afternoon $\left(^{\circ}\right)$ \\
\hline
\end{tabular}

etc. Kacira et al. (2004) experimentally investigated the effect of a dual-axis solar tracking on energy gain compared to a fixed panel in Sanliurfa of Turkey, and found that the daily average gain is $29.3 \%$ in solar radiation and $34.6 \%$ in power generation, for a particular day in July.

Abu-Khader et al. (2008) performed an experimental investigation on the effect of using two-axis sun-tracking systems on the electrical generation of a flat photovoltaic system to evaluate its performance under Jordanian climate. It was experimentally found that there was an increase of about $30-45 \%$ in the output power for the North-South axes-tracking system compared to the fixed PV system, for particular days.

All the above-mentioned studies either focuses on the theoretical prediction of long-term solar radiation gain for continuous sun-tracking PV or reported test results of electrical generation of sun-tracking PV for particular days only. The test result of long-term overall performance of a sun-tracking PV system is very rare.

In the present study, 1 axis-3 position (1A-3P) sun tracker (Fig. 1) was designed base on the research results of Huang and Sun (2007) and tested with a stand-alone PV system. The 1A-3P tracker operates only at 3 different angles (morning, noon, and afternoon) as shown in Fig. 1. The analytical results (Huang and Sun, 2007) have shown that the optimal stopping angle $\beta$ in the morning or afternoon is $50^{\circ}$ from the solar noon position and the optimal turning angle (the time to turn the tracker) that controls

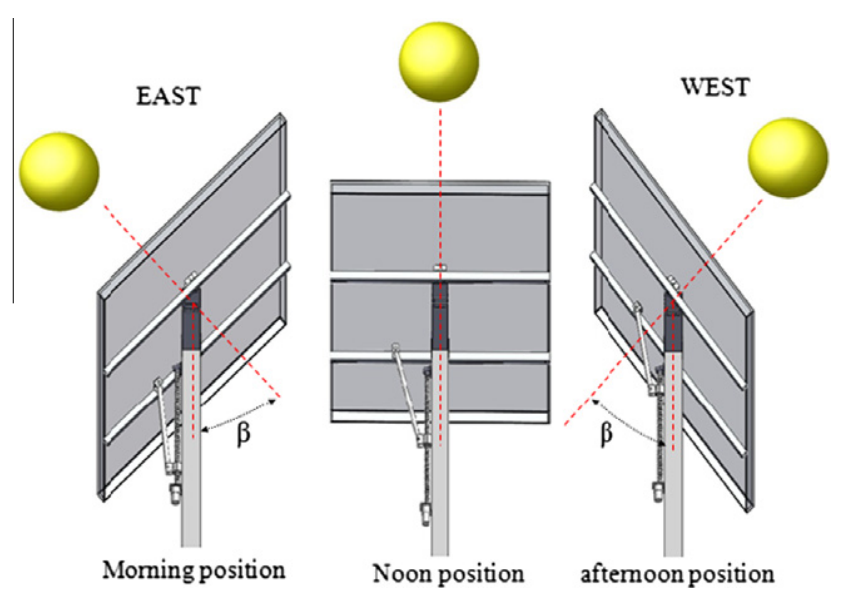

Fig. 1. 1 axis-3 position (1A-3P) sun tracker. the best time for changing the attitude of the PV module is half of the stopping angle, i.e. $25^{\circ}$, and both are independent of the latitude. The analysis also shows that the total solar energy capture of 1A-3P tracking PV increases by $24.5 \%$ as compared to a fixed PV module for latitude $<50^{\circ}$.

The 1A-3P tracking PV has many advantages, including simple structural design which is cheaper and easy to be mounted on buildings, limited control action for three positions only which will greatly reduce the tracking malfunctions due to disturbance or noises of environment, and low cost for the whole system.

It is known that the actual power generation of tracking PV may not be proportional to the estimated solar energy capture since there may be some losses in PV module performance such as temperature effect of solar cell and battery charging loss, and the unexpected diffuse solar radiation variation may exist all the time. An investigation made by Kelly and Gibson (2009) has shown that during cloudy periods, a horizontal module orientation increases the solar energy capture by nearly $50 \%$ compared to 2 -axis solar tracking during the same period.

The present study intends to perform daily and longterm test for two identical stand-alone solar PV systems to compare the actual overall $\mathrm{PV}$ power generation from 1A-3P sun tracking and the fixed PV systems.

\section{Design of 1A-3P tracker}

The mechanism of 1A-3P sun tracker consists of 3 major components: PV mounting frame, supporting frame, and turning mechanism, as shown in Fig. 2. The cost is thus very low in mass production. Fig. 3 shows the installation of $1 \mathrm{X}-3 \mathrm{P}$ sun tracking PV on a vertical wall of a building. This can save the installation and land costs for buildingintegrated applications.

Several engineering approaches to continuously track the sun using one-axis open-loop (Kalogirou, 1996), twoaxis closed-loop (Lynch and Salameh, 1990) and two-axis open-loop (Park et al., 1996) tracking have been proposed. There are many different controllers to implement the control schemes, e.g. PLA (programmable logic array) (Abouzeid, 2001), PLC (Abdallah and Nijmeh, 2004), PC (Yousef, 1999) and micro-processor (Koyuncu and Balasubramanian, 1991). The continuous tracking of sun motion in the conventional one-axis or two-axis tracker is 


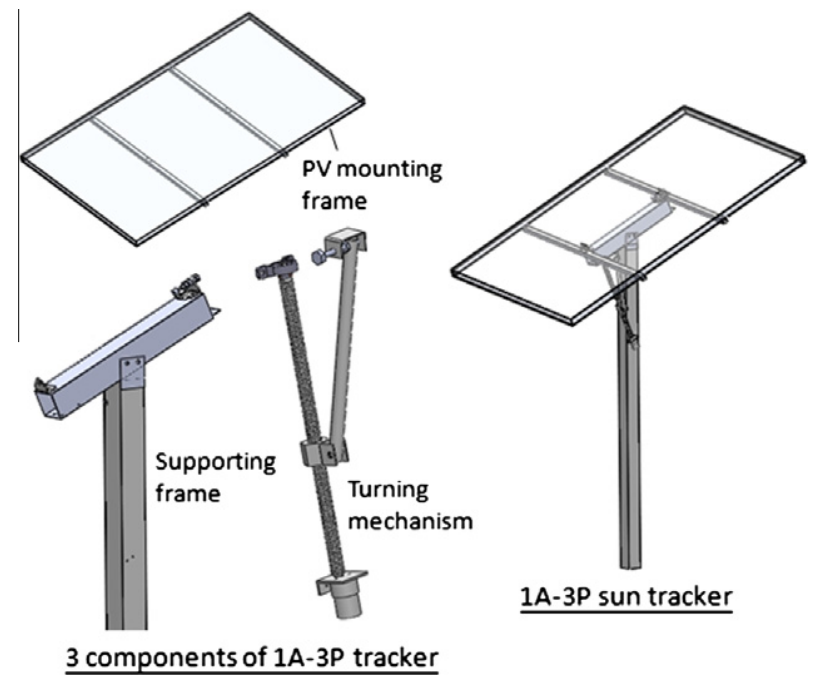

Fig. 2. Simple 1A-3P sun tracker design.

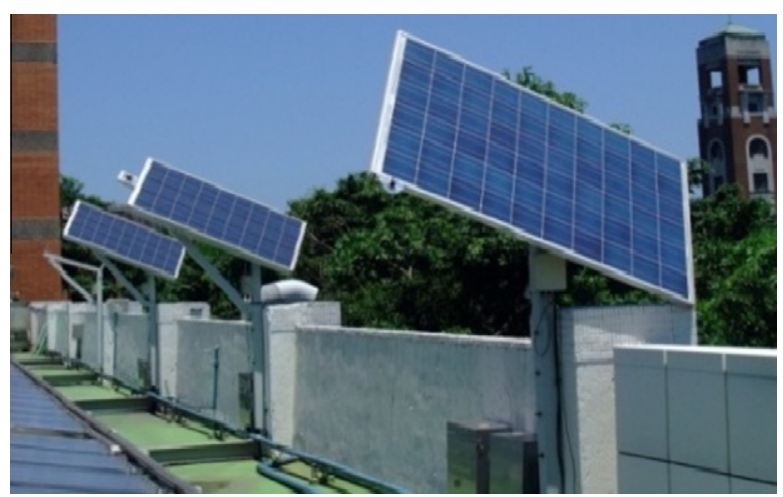

Fig. 3. $1 \mathrm{~A}-3 \mathrm{P}$ sun tracking $\mathrm{PV}$ installation.

subject to some reliability problems in control system such as failure of sensors, malfunction of tracking signal processing due to noise or disturbances etc.

For the present $1 \mathrm{~A}-3 \mathrm{P}$ sun tracker, a DC motor is used to turn the PV mounting frame. The turning of the $1 \mathrm{~A}-3 \mathrm{P}$ tracker is made by a timer IC which is used to provide the time signal to trigger the motor to turn at the turning angle (or time). The motor consumes $5 \mathrm{~W}$ power and it takes about $15 \mathrm{~s}$ for each turning. The energy consumption of the driving motor is thus negligible. A rotating-type resistor was installed on the rotating axis as the position sensor to detect the angular position of the tracker to control the stopping angle. All the control algorithms, measuring functions for tracker motion and $\mathrm{PV}$ power generation, was implemented by a micro-processor PIC18F452. The instantaneous solar irradiation on the fixed PV with tilt angle $25^{\circ}$ $\left(I_{T}\right)$ was measured every $4 \mathrm{~s}$. The daily-total solar irradiation on the fixed PV tilt $\left(H_{T}\right)$ was integrated from measured $I_{T}$.

The comparative test was carried out using one fixed PV and one $1 \mathrm{~A}-3 \mathrm{P}$ tracking $\mathrm{PV}$ with the identical stand-alone solar-powered LED lighting system (sLED). The fixed PV module was installed at $25^{\circ}$ tilted angle (the latitude of Tai- pei), the same tilted angle of $1 \mathrm{~A}-3 \mathrm{P}$ tracker, both facing south.

\section{Design of stand-alone solar PV system for comparative test}

The stand-alone solar power system is widely used in remote areas where the grid power cannot reach. Fig. 4 shows the schematic diagram of the sLED which was developed by National Taiwan University. The sLED consists of a photovoltaic module (PV) to generate electric power, a lead-acid battery to store the generated electrical energy at day time (solid line), and a load (LED) to discharge energy for lighting at night.

The solar PV module of the sLED is usually connected to a maximum-power-point-tracking controller (MPPT) to regulate the $\mathrm{PV}$ power output at the maximum power point to obtain optimal power generation. A DC/DC converter needs to be added after the MPPT in order to convert the MPPT output voltage into the battery charging voltage. However, the MPPT can be replaced with a so-called "near-maximum-power-point-operation design (nMPPO)" of the PV power generation system developed by Huang et al. (2006). The nMPPO simply properly matches the PV module operating characteristics with the battery voltage in the system design to obtain a performance similar to that of MPPT. The additional cost, reliability problem, and energy loss experienced with the MPPT and the DC/DC converter is thus avoided.

To charge the battery to its full capacity and provide battery charging protection, a three-phase charge algorithm (Fig. 5) was employed by using pulse-width-modulation (PWM) technique to reduce the charging current to maintain the battery voltage at its overcharge voltage to avoid overcharge in Phase 2 and prolong the life of the battery (Huang et al., 2010a).

To improve the efficiency of sLED, a PWM battery discharge controller to directly drive the LED for lighting was developed by Huang et al. (2010b) and used in the present study.

For comparative test purpose, a $100 \mathrm{~W}$ LED lighting fixture (Model: SL-100-S2, $24 \mathrm{~V} / 100 \mathrm{~W}$, by ATD, Inc.) was chosen as the load of the sLED. The $100 \mathrm{~W}$ LED light system, designed according to Huang et al. (2010b),

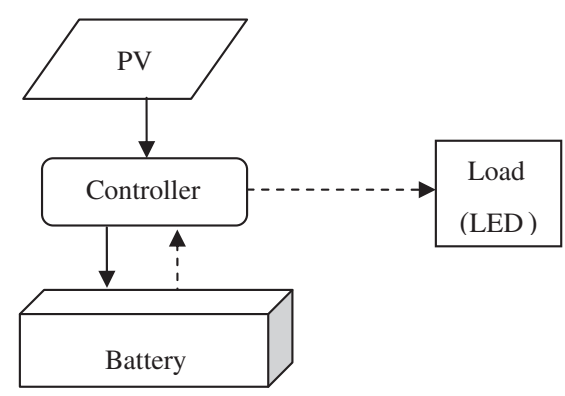

Fig. 4. Stand-alone solar power system. 


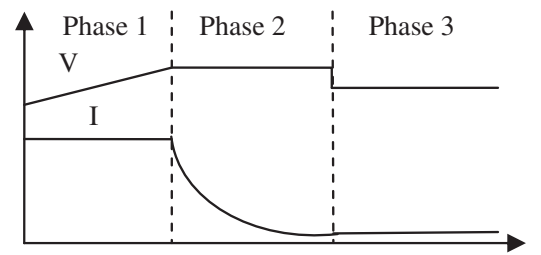

Fig. 5. Three-phase battery charging algorithm.

includes a $230 \mathrm{Wp}$ PV module (DST230P660S, made by DST Energo, rated conversion efficiency $15 \%$ ) and two lead-acid batteries connected in series (Pilot PLG10012HLM, $12 \mathrm{~V} / 100 \mathrm{Ah})$.

\section{Test results and discussions}

\subsection{Performance in particular days}

The power generation increase of $1 \mathrm{~A}-3 \mathrm{P} \mathrm{PV}, E_{\text {inc }}$, is defined as:

$E_{\text {Inc }}=\frac{\text { power generation of } 1 \mathrm{~A}-3 \mathrm{P}-\text { power generation of fix }}{\text { power generation of fixed } \mathrm{PV}}$

The test result of a typical day (2010/5/25) shown in Fig. 6, it is shown that the $1 \mathrm{~A}-3 \mathrm{P}$ tracking PV generates $34.6 \%$ more electricity than the fixed PV. The weather is clear with $H_{T}=19.9 \mathrm{MJ} / \mathrm{m}^{2}$ day and the instantaneous $\mathrm{PV}$ power generation of $1 \mathrm{~A}-3 \mathrm{P} \mathrm{PV}$ is much higher than the fixed PV during the morning and afternoon. During noon-time period, both 1A-3P and fixed PV generate about the same amount of electricity. A similar test result on September 25, 2010, with daily-total solar irradiation $H_{T}=18.5 \mathrm{MJ} / \mathrm{m}^{2}$ (sunny weather) also shows that the increase of daily-total power generation for the 1A-3P tracking PV is $35.6 \%$. Another measured increase of the daily-total power generation from the $1 \mathrm{~A}-3 \mathrm{P}$ sun tracking $\mathrm{PV}$ is $35.8 \%$ on March 5, 2010, with $H_{T}=11.7 \mathrm{MJ} /$ $\mathrm{m}^{2}$ day (partly-cloudy weather). Kacira et al. (2004) experimentally investigated the effect of dual-axis sun-tracking on the energy gain as compared with a fixed PV panel in Sanliurfa, Turkey, and found that the gross gain was $29.3 \%$ in solar radiation and $34.6 \%$ in power generation for a particular day in July, which is the about same as Fig. 6 for 1A-3P tracking PV. This indicates that the present 1A-3P tracking PV can perform very close to a dualaxis continuous tracking PV for particular days.

The battery of the sLED will discharge electricity for the lighting of $100 \mathrm{~W}$ LED at night. Fig. 7 shows the variation of battery charging voltage and current of the 1A-3P PV and the fixed PV during the day. It is seen that the battery voltages of both sLED are very close and always below the overcharge point $(28.6 \mathrm{~V})$ and the charging current stays at Phase I. This makes the comparison of PV power generation, i.e. the charged energy to the battery, to be on a common basis and more accurate. The battery voltage of the fixed PV is a little bit smaller than that of the 1A-3P PV since the power generation of the fixed PV is less than the 1A-3P PV and the electricity discharge at night for $100 \mathrm{~W}$ LED are the same for both sLED.

\subsection{Long-term test results}

A long-term performance test of the sLED with 1A-3P sun tracking PV and fixed PV was carried out to investigate the effect of long-term weather change. The outdoor test starts from March 1, 2010. Some data were lost in June and July, and 13 days in August due to malfunction of the recorder. The test results show that the highest increase of daily power generation from 1A-3P sun tracking PV is $35.8 \%$ on March 5, 2010, with daily-total solar irradiation

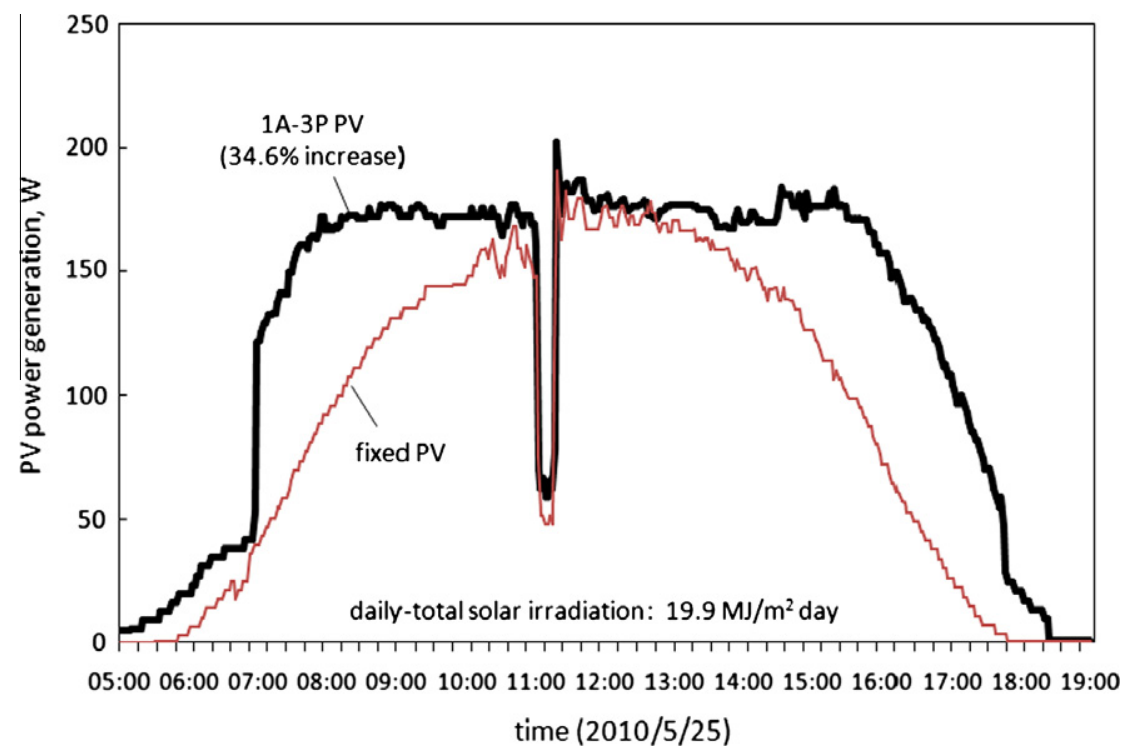

Fig. 6. Solar power generation of 1A-3P tracking PV and fixed PV. 


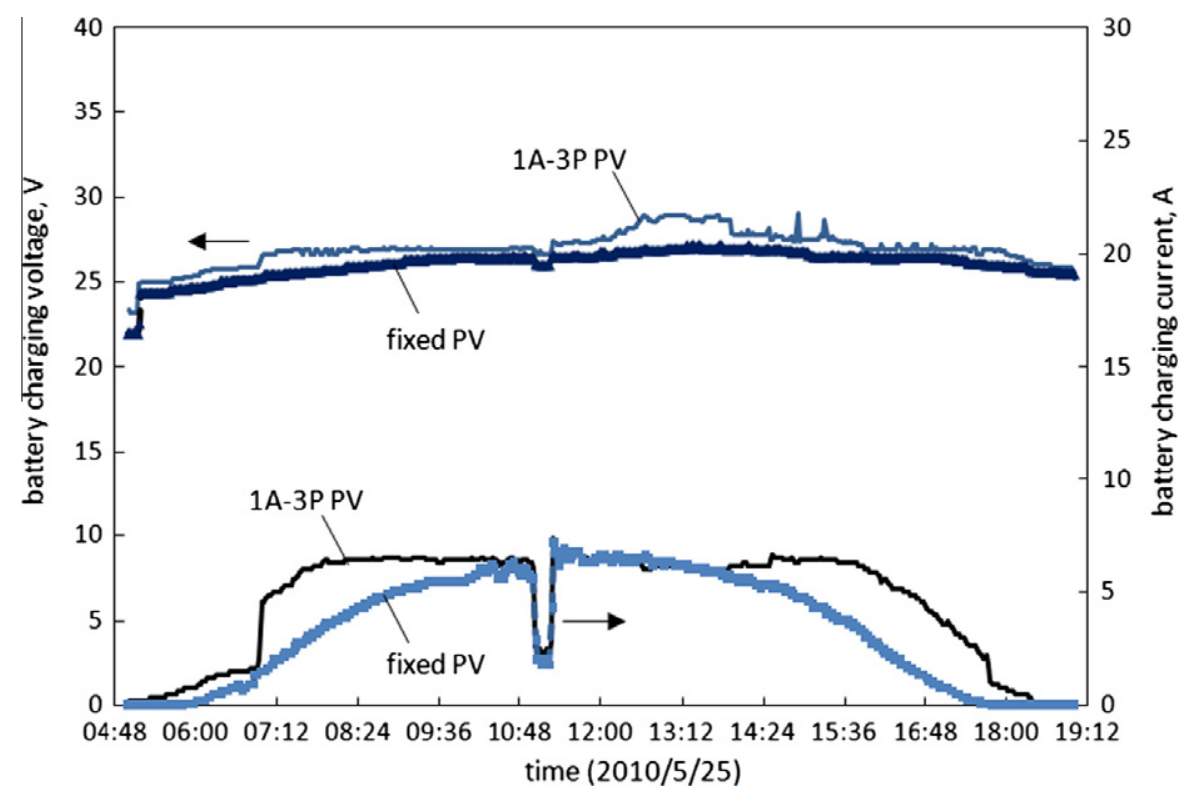

Fig. 7. Battery charging voltage and current.

$H_{T}=11.7 \mathrm{MJ} / \mathrm{m}^{2}$ day (partly-cloudy weather) and $35.6 \%$ on September 25, 2010, with daily-total solar irradiation $H_{T}=18.5 \mathrm{MJ} / \mathrm{m}^{2}$ day (sunny weather). In general, the power generation of 1A-3P PV usually increases much more on clear weather $\left(H_{T}>15 \mathrm{MJ} / \mathrm{m}^{2}\right.$ day $)$. But in some partly-cloudy days $\left(H_{T}=10-15 \mathrm{MJ} / \mathrm{m}^{2}\right.$ day $)$, the increase of power generation is still obvious. This may be due to the unexpected variation of the diffuse radiation from sky, cloud, or ground.

Figs. 8 and 9 present the daily performance in March, and September, respectively, which represents spring and summer seasons. It shows that the increase of 1A-3P PV power generation increases with daily solar irradiation.

Fig. 10 summarizes the variation of daily power generation increase of $1 \mathrm{~A}-3 \mathrm{P} \mathrm{PV}$ with solar irradiation in the long-term test. It is seen that power generation increase greater than $22 \%$ can be expected in clear days $\left(H_{T}>15 \mathrm{MJ} / \mathrm{m}^{2}\right.$ day).

The monthly test results of Table 1 show that the increase of monthly-total power generation from 1A-3P sun tracking PV is between $18.5 \%$ and $28.0 \%$. The total power generation increase in the test period from March 1, 2010 to March 31, 2011, is $23.6 \%$ which is very close to the theoretical prediction of solar energy capture $(24.5 \%)$ by Huang and Sun (2007).

Chang (2009) carried out a theoretical calculation of yearly gains for a single-axis continuous tracking PV installed at Taichung, central Taiwan, with the yearly optimal tilt angle (latitude). It was found that the yearly gain is $28.5 \%$. This is very close to the present long-term test

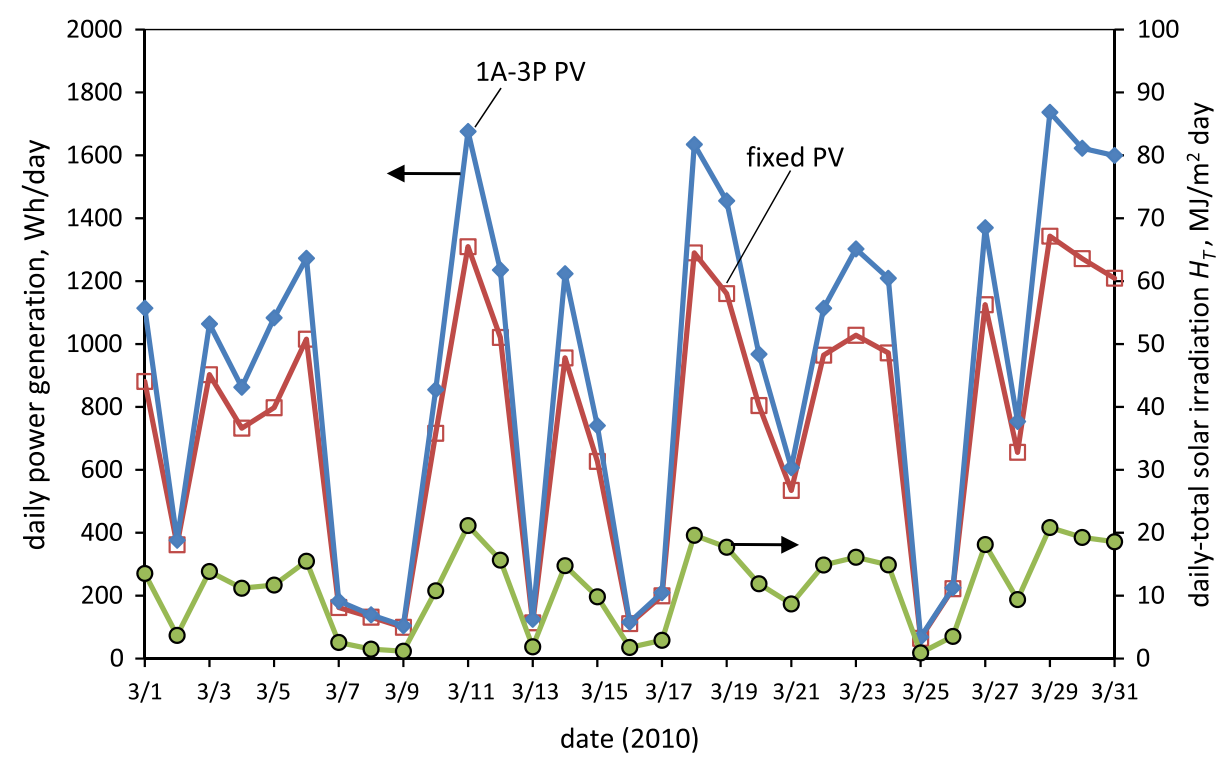

Fig. 8. Long-term test results of 1A-3P tracking PV and fixed PV (March, 2010). 


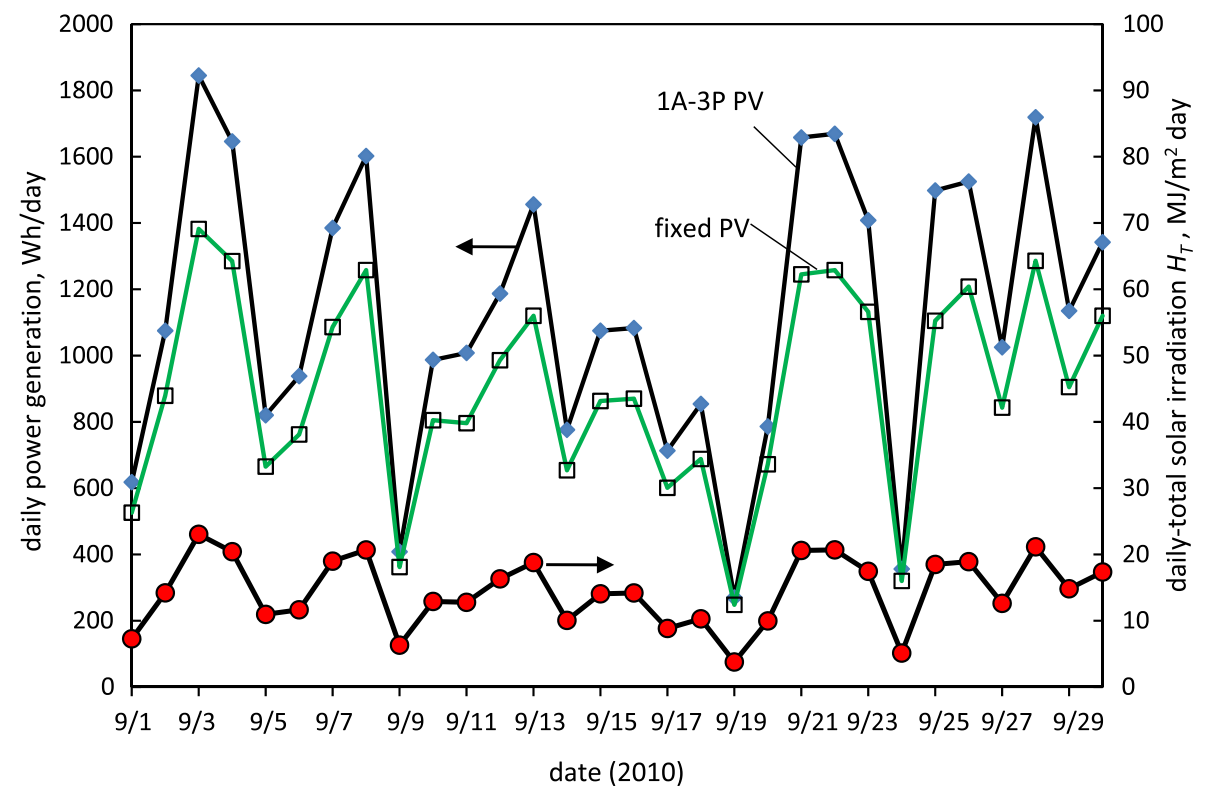

Fig. 9. Long-term test results of 1A-3P tracking PV and fixed PV (September, 2010).

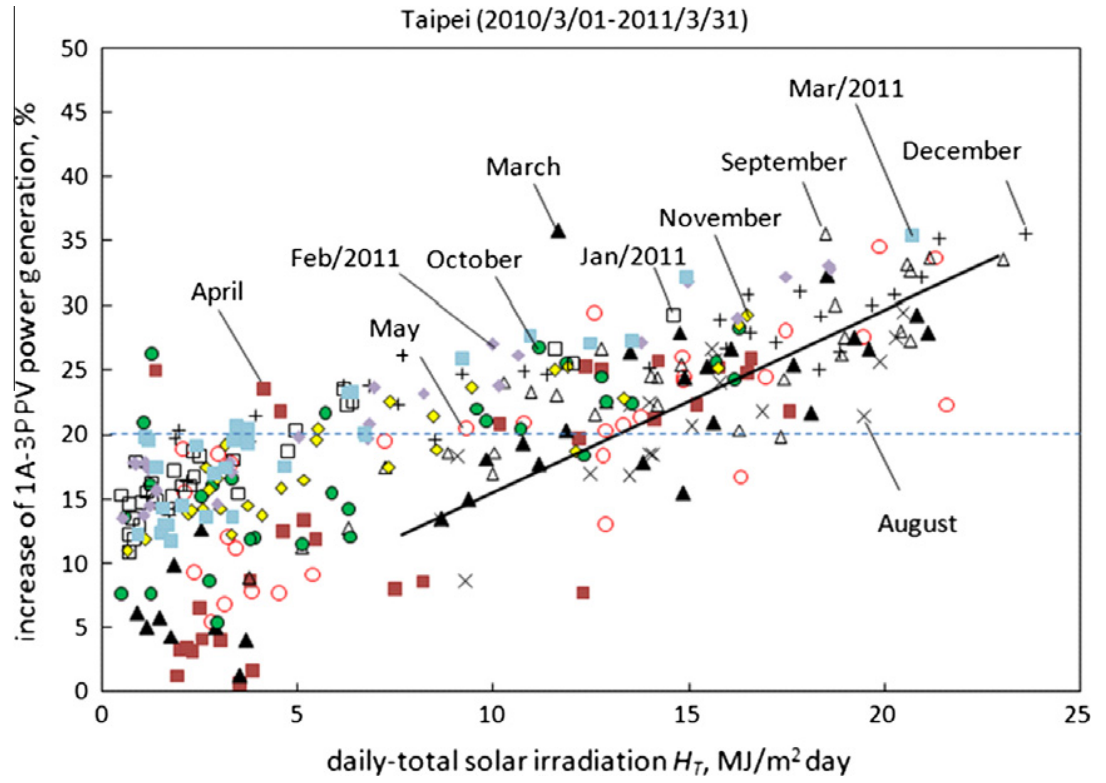

Fig. 10. Daily power generation increase of 1A-3P PV.

results since the solar irradiation in Taichung is about $20 \%$ higher than that in Taipei. This means that the 1-axis 3position tracking PV performs very close to the 1-axis continuous tracking in Taiwan.

In the present long-term field test, some data were lost during summer due to malfunction of the recorder. However, the available test results during August 7-24 shows that the average daily-total solar irradiation $H_{T}$ is $14.89 \mathrm{MJ} / \mathrm{m}^{2}$ day which can represent the typical summer weather in June and July in Taipei. Fig. 10 also shows that there are many daily performances made at $H_{T}>15 \mathrm{MJ} /$ $\mathrm{m}^{2}$ day in December, which also can represent the weather in summer. The only difference in PV system performance in summer and winter is the PV module temperature which will be lower in winter (about $20^{\circ} \mathrm{C}$ lower) and cause higher energy conversion efficiency of PV module (about $10 \%$ higher).

The above results indicates that the long-term total power generation increase of a $1 \mathrm{~A}-3 \mathrm{P}$ tracking $\mathrm{PV}$ with respect to fixed PV in areas with abundant solar energy resource (high $H_{T}$ ) will be larger than the present test result $(23.6 \%)$ which was made in Taipei area with low solar energy resource. The yearly-mean daily solar irradiation is about $10.7 \mathrm{MJ} / \mathrm{m}^{2}$ day in Taipei from local weather station. If 1A-3P tracking PV is used in the area of high solar energy resource with average daily solar irradiation $>17 \mathrm{MJ} / \mathrm{m}^{2}$ day, the expected increase of long-term total power generation with respect to fixed PV will be 
Table 1

Monthly-total power generation.

\begin{tabular}{|c|c|c|c|c|c|}
\hline $\begin{array}{l}\text { Month } \\
(2010)\end{array}$ & $\begin{array}{l}\text { Monthly-total solar } \\
\text { irradiation (MJ } / \mathrm{m}^{2} \text { month) }\end{array}$ & $\begin{array}{l}\text { Monthly-average daily-total solar } \\
\text { irradiation } H_{T}\left(\mathrm{MJ} / \mathrm{m}^{2} \text { day }\right)\end{array}$ & $\begin{array}{l}\text { Power generation } \\
\text { 1A-3P PV }(\mathrm{Wh})\end{array}$ & $\begin{array}{l}\text { Power generation } \\
\text { fixed } \mathrm{PV}(\mathrm{Wh})\end{array}$ & $\begin{array}{l}\text { Increase of PV power } \\
\text { generation }\left(E_{\text {inc }}\right),(\%)\end{array}$ \\
\hline March & 348 & 11.21 & 28,044 & 22,783 & 23.1 \\
\hline April & 239 & 7.96 & 17,136 & 14,466 & 18.5 \\
\hline May & 323 & 10.41 & 25,082 & 20,464 & 22.6 \\
\hline $\begin{array}{l}\text { August }(8 / \\
7-8 / 24)\end{array}$ & 268 & 14.89 & 17,604 & 14,427 & 22.0 \\
\hline Sept & 433 & 14.42 & 33,867 & 26,930 & 25.8 \\
\hline Oct & 213 & 6.86 & 15,908 & 13,162 & 20.9 \\
\hline Nov & 196 & 6.53 & 14,654 & 12,041 & 21.7 \\
\hline Dec & 365 & 11.76 & 28,733 & 22,451 & 28.0 \\
\hline $\operatorname{Jan}(2011)$ & 103 & 3.32 & 8,386 & 6,911 & 21.3 \\
\hline $\mathrm{Feb}(2011)$ & 189 & 6.76 & 15,100 & 11,958 & 26.3 \\
\hline $\operatorname{Mar}(2011)$ & 160 & 5.16 & 12,527 & 10,067 & 24.4 \\
\hline Total & 2,835 & - & 217,040 & 175,659 & 23.6 \\
\hline
\end{tabular}

higher than $37.5 \%(=23.6 \% \times 17 / 10.7)$. This is very close to the dual-axis continuous tracking PV (Kacira et al., 2004). The similar conclusion was also recently made by Koussa et al. (2011). It was experimentally shown that the two-axis sun tracking system presents a small additional amount of electrical energy generation with respect to that produced by the different single-axis sun tracking systems. The use of the two-axis system cannot be justified unless the amount of produced electrical energy compensates for the additional equipment, related energy consumption, maintenance and corresponding additional structure elements costs.

\subsection{System performance reliability}

The reliability of the sun tracking PV is very important since the lifetime of a solar PV system has to be longer than
20 years. The reliability problems may arise from the error of timer IC, mechanism failure, position sensor failure, controller failure due to disturbances or noises etc. All the designs based on continuous 1-axis or 2-axis tracking device are complicated, expensive, less reliable, and may not obtain high efficiency in long-term performance.

A test for the controller of $1 \mathrm{~A}-3 \mathrm{P}$ sun tracker utilizing the timer IC shows that the real time error is about $0.6 \mathrm{~s}$ per day (Fig. 11). That is, about $30 \mathrm{~min}$ for 10 years operation which is acceptable.

The 1A-3P sun tracker has been tested continuously for 13 months and ever been hit by a big typhoon with maximum wind speed $50 \mathrm{~m} \mathrm{~s}^{-1}$ in September, 2010. It shows no any damage and no any failure in the tracker motion. Fig. 12 shows that the long-term tracker motion from March 1 to May 1, 2010, is perfect. The $100 \mathrm{~W}$ sLED tested with this sun tracker shows that the performance is

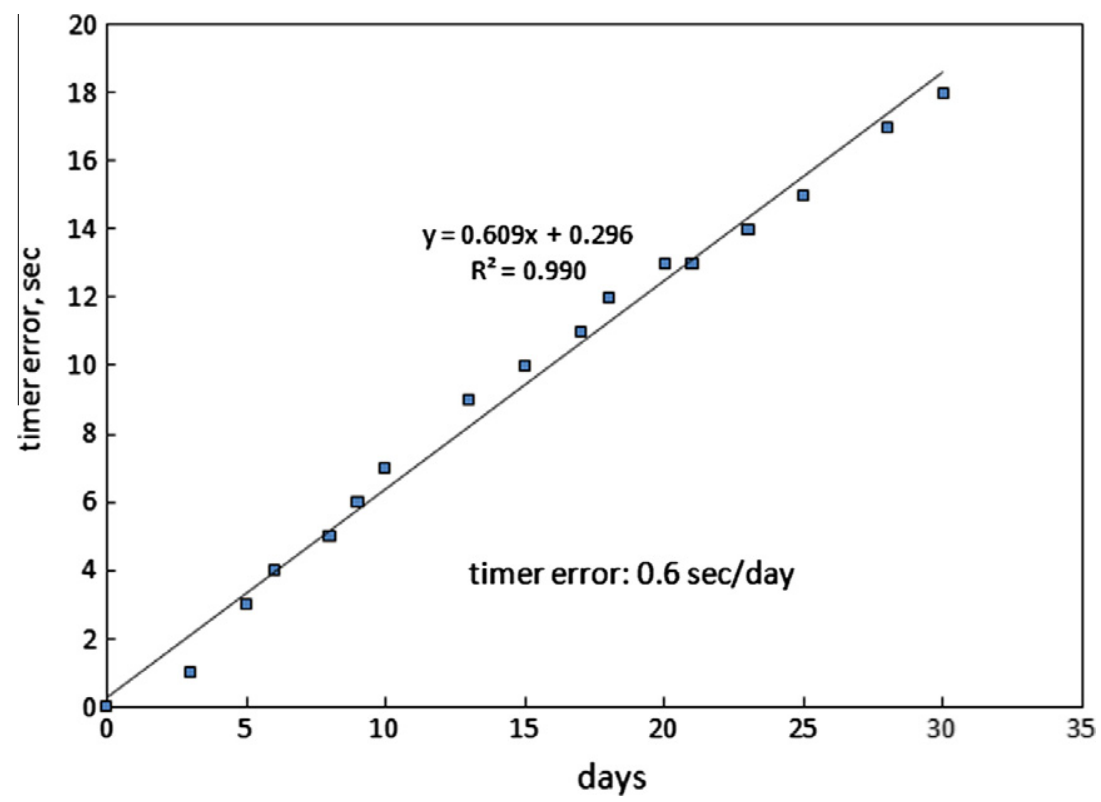

Fig. 11. Test of timer error. 


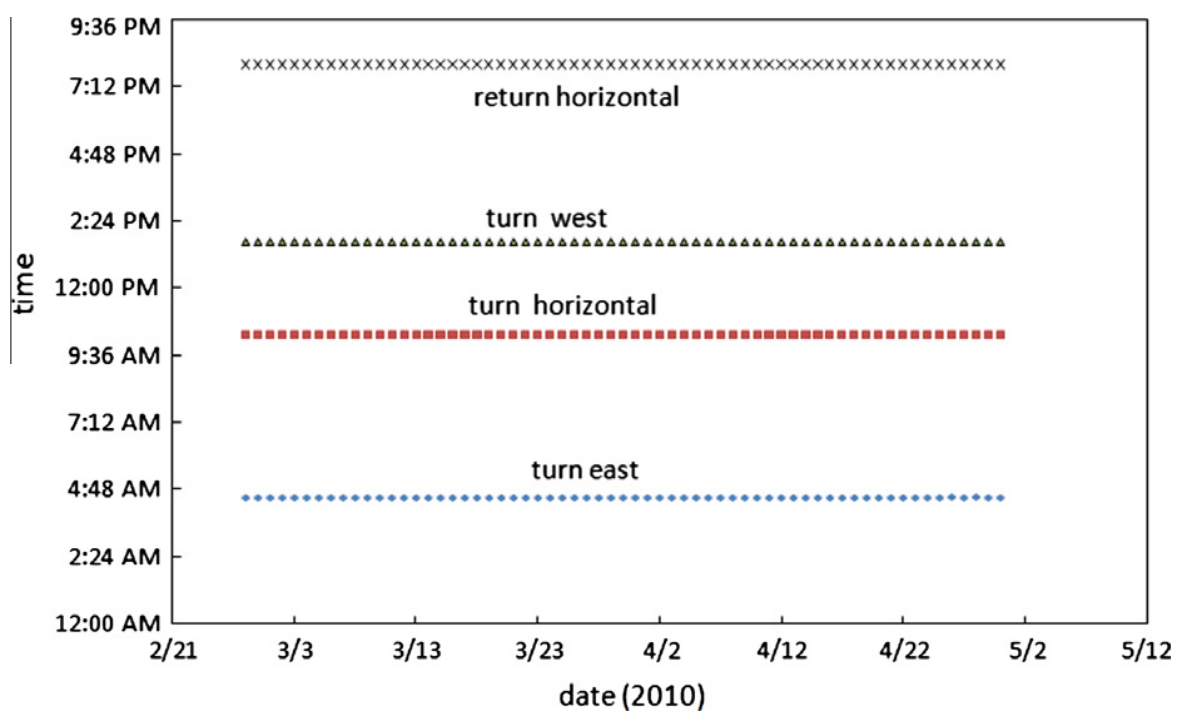

Fig. 12. Long-term test of tracker motion.

satisfactory. Fig. 13 shows that the LED turns off earlier (by midnight) for only 7 nights from March 1 to May 10, 2010, due to poor solar radiation.

There is another side benefit using 1A-3P sun tracker. It has been shown by Huang and Sun (2007) that the optimal stopping angle $\beta$ is $50^{\circ}$, independent of the installation location, which is relatively steep and can easily swipe off the dust covered on the PV module. This is quite promising when used in dessert area having dust problems.

\subsection{Cost issue of 1A-3P tracking $P V$}

The cost of 1A-3P tracker is much cheaper due to simple design which is suitable for mass production. If the PV power generation system was installed on rooftop of a building, the cost for the mounting structure to withstand strong wind, typhoon, or earthquake, and the waterproof of roof surface is very high. Usually, it will cost about USD 100 for each PV module (200-300 Wp per module) mounted on roof. The structural design of 1A-3P tracker is very simple since it is a one-axis tracker which can be easily mounted on the wall of a building. The cost of the whole tracker including structure, driving mechanism, motor, and controller is around USD 100 in mass production, about the same as the regular mounting cost of rooftop PV system. This means that there is no extra cost for 1A-3P PV mounted on buildings but the power generation can increase $23.6 \%$ (in Taipei) or higher in areas with abundant solar energy resource. The additional space of rooftop floor for installing 1A-3P tracking PV can also be saved.

For PV tracker mounted on ground surface, $10 \%$ of the whole PV system cost (about USD 500 per $\mathrm{kWp}$ ) will be spent on the conventional one-axis tracker and 25-30\% (about USD1 250-1500 per kWp) will be spent for two-axis

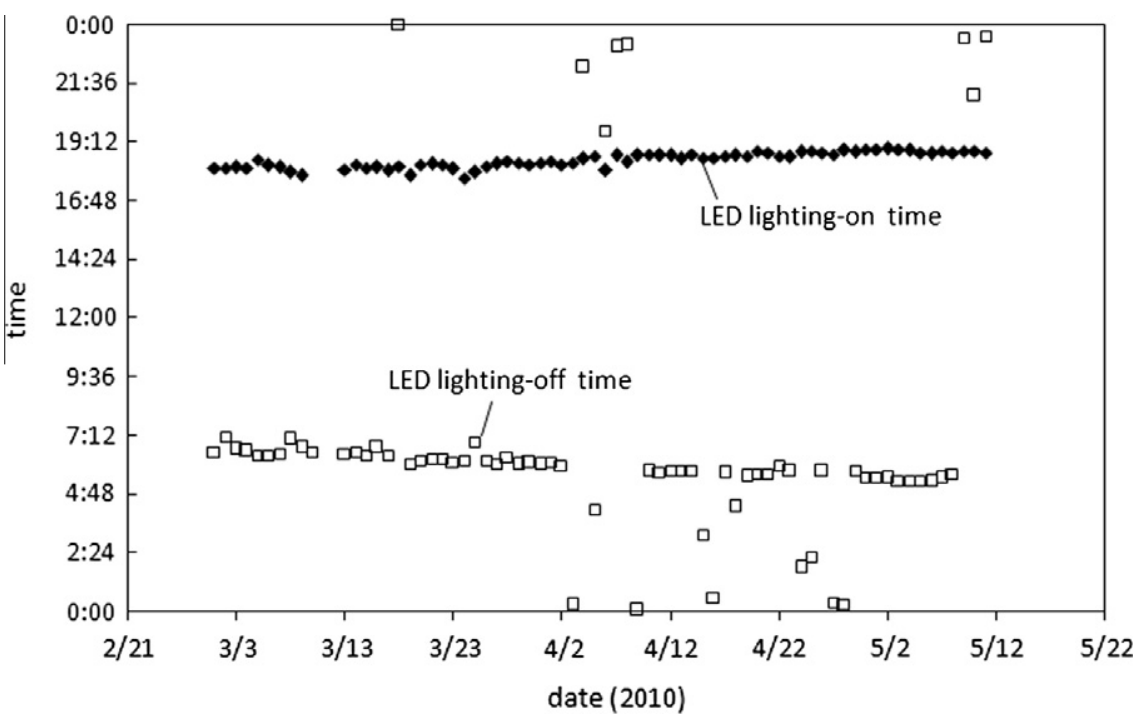

Fig. 13. Lighting test of sLED (100W) with 1A-3P sun tracking PV. 
tracker, including structure, driving mechanism, motor, and controller. For 1A-3P tracker, the additional cost for mounting on ground using automatic drilling machine is about USD100 each. For $300 \mathrm{Wp} \mathrm{PV} \mathrm{module} \mathrm{carried} \mathrm{by}$ each tracker, this means that the total cost of $1 \mathrm{~A}-3 \mathrm{P}$ tracker is USD 200 per tracker, or USD 660 per $\mathrm{kWp}$. If the PV module carried is larger than $600 \mathrm{Wp}$ per module, the total cost will be less than USD200 per $600 \mathrm{Wp}$, or USD 330 per $\mathrm{kWp}$, which is cost competitive to the conventional tracker.

It is concluded that the present $1 \mathrm{~A}-3 \mathrm{P}$ PV is quite suitable for building-integrated applications. But the ground mounting of $1 \mathrm{~A}-3 \mathrm{P}$ tracker is also economically feasible if the PV module carried by each tracker is $>600 \mathrm{Wp}$.

\section{Conclusion}

The tracking flat PV system is one of the methods to increase the PV power generation. The present 1 axis-3 position (1A-3P) sun tracker was designed based on the previous research by Huang and Sun (2007). The 1A-3P tracker operates only at 3 different angles daily. The optimal stopping angle in the morning or afternoon is $50^{\circ}$ from the solar noon position and the optimal turning angle that controls the best time for turning the PV module is half of the stopping angle, i.e. $25^{\circ}$, and both are independent of the latitude.

A comparative test using fixed PV and 1A-3P tracking PV was carried out in the present study with two identical stand-alone solar-powered LED lighting systems (sLED) consisting of a 100W LED light, a $230 \mathrm{Wp} \mathrm{PV} \mathrm{module,}$ and two lead-acid batteries $(100 \mathrm{Ah} / 12 \mathrm{~V})$ connected in series. The motion of the tracker is activated by the signal of an IC timer with a micro-processor based controller which triggers the motor at the pre-determined time. A rotatingtype position sensor was installed on the rotating shaft to detect the angular position of the tracker.

The field test result of a typical clear day $(2010 / 5 / 25)$ shows that the 1A-3P tracking PV generates $34.6 \%$ more electricity than the fixed PV at clear weather with $H_{T}=19.9 \mathrm{MJ} / \mathrm{m}^{2}$ day. A similar test result on September 25,2010 , with $H_{T}=18.5 \mathrm{MJ} / \mathrm{m}^{2}$ (sunny day) also shows that the increase of daily-total power generation for the 1A-3P tracking $\mathrm{PV}$ is $35.6 \%$. This indicates that the present $1 \mathrm{~A}-$ $3 \mathrm{P}$ tracking $\mathrm{PV}$ can perform very close to a dual-axis continuous tracking PV for particular days (Kacira et al., 2004).

The increase of monthly-total power generation from 1A-3P sun tracking PV is between $18.5 \%$ and $25.8 \%$. The long-term total power generation increase in the test period from March 1, 2010, to March 31, 2011, is 23.6\% which is very close to the theoretical prediction by Huang and Sun (2007). The present 1A-3P tracking PV performs very close to the conventional 1 -axis continuous tracking PV in Taiwan (Chang, 2009).

From the present long-term field test results, it can be shown that if $1 \mathrm{~A}-3 \mathrm{P}$ tracking $\mathrm{PV}$ is used in the area of high solar energy resource with average daily solar irradia- tion $>17 \mathrm{MJ} / \mathrm{m}^{2}$ day, the expected increase of total longterm power generation with respect to fixed $\mathrm{PV}$ will be higher than $37.5 \%$. This is very close to the performance of dual-axis continuous tracking PV (Kacira et al., 2004). This conclusion also supports the recent research results by Koussa et al. (2011) who experimentally showed that the two-axis sun tracking PV system presents only a small additional amount of electrical energy generation with respect to that produced by the different single-axis sun tracking systems.

The reliability problems of the sun tracking PV may arise from the error of timer IC, mechanism failure, and position sensor failure etc. A test of the controller of 1A$3 \mathrm{P}$ sun tracker shows that the real time error is about $0.6 \mathrm{~s}$ per day. That is, about $30 \mathrm{~min}$ for 10 years operation and which is acceptable.

The sun tracker has been tested continuously for 13 months and ever been strike a big typhoon with maximum wind speed $50 \mathrm{~m} \mathrm{~s}^{-1}$ in September. It shows no any damage and no any failure in the tracker motion. The $100 \mathrm{~W}$ sLED tested with this sun tracker shows that the performance is satisfactory.

The cost of 1A-3P PV is much cheaper as compared to conventional PV tracking system. The 1A-3P tracker is very simple in design and can be easily mounted on the wall of a building. The cost of the whole tracker including structure, driving mechanism, motor, and controller is around USD 100 in mass production, about the same as the regular mounting cost of a rooftop PV system. This means that there is no extra cost for 1A-3P PV mounted on buildings but the power generation can increase about $23.6 \%$ in Taipei or higher depending on the installation area. The additional land cost of 1A-3P tracking PV can also be saved for building-integrated installation.

It is concluded that $1 \mathrm{~A}-3 \mathrm{P} \mathrm{PV}$ is suitable for buildingintegrated applications. But the ground mounting of $1 \mathrm{~A}-$ 3P tracker is also economically feasible if the PV module carried by each tracker is $>600 \mathrm{Wp}$.

\section{Acknowledgement}

This publication is based on work supported by Award No. KUK-C1-014-12, made by King Abdullah University of Science and Technology (KAUST), Saudi Arabia.

\section{References}

Abdallah, S., Nijmeh, S., 2004. Two axes sun tracking system with PLC control. Energy Conversion and Management 45, 1931-1939.

Abouzeid, M., 2001. Use of a reluctance stepper motor for solar tracking based on a programmable logic array (PLA) controller. Renew Energy 23, 551-560.

Abu-Khader, Mazen M., Badran, Omar O., Abdallah, Salah, 2008. Evaluating multi-axes sun-tracking system at different modes of operation in Jordan. Renewable and Sustainable Energy Reviews 12, 864-873.

Chang, T.P., 2009. Output energy of photovoltaic module mounted on a single-axis tracking system. Applied Energy 86 (10), 2071-2078. 
Huang, B.J., Sun, F.S., 2007. Feasibility study of 1-axis three-position tracking solar PV with low concentration ratio reflector. Energy Conversion and Management 48, 1273-1280.

Huang, B.J., Sun, F.S., Ho, R.W., 2006. Near-maximum-power-pointoperation (nMPPO) design of photovoltaic power generation system. Solar Energy 80, 1003-1020.

Huang, B.J., Hsu, P.C., Wu, M.S., Ho, P.Y., 2010a. System dynamic model and charging control of lead-acid battery for stand-alone solar PV system. Solar Energy 84, 822-830.

Huang, B.J., Wu, M.S., Hsu, P.C., Chen, J.W., Chen, K.Y., 2010 b. Development of high- performance solar LED lighting system. Energy Conversion and Management 51, 1669-1675.

Kacira, M., Simsek, M., Babur, Y., Demirkol, S., 2004. Determining optimum tilt angles and orientations of photovoltaic panels in Sanliurfa, Turkey. Renewable Energy 29, 1265-1275.

Kalogirou, S.A., 1996. Design and construction of a one-axis sun-tracking system. Solar Energy 57 (6), 465-469.

Kelly, Nelson A., Gibson, Thomas L., 2009. Improved photovoltaic energy output for cloudy conditions with a solar tracking system. Solar Energy 83, 2092-2102.
Koussa, M., Cheknane, A., Hadji, S., Haddadi, M., Noureddine, S., 2011. Measured and modelled improvement in solar energy yield from flat plate photovoltaic systems utilizing different tracking systems and under a range of environmental conditions. Applied Energy 88 (5), $1756-1771$.

Koyuncu, B., Balasubramanian, K., 1991. A microprocessor controlled automatic sun tracker. IEEE Transactions on Consumer Electronics 37 (4), 913-917.

Li, Z., Liu, X., Tang, T., 2010. Optical performance of inclined southnorth single-axis tracked solar panels. Energy 35, 2511-2516.

Lynch, W.A., Salameh, Z.M., 1990. Simple electro-optically controlled dual axis sun tracker. Solar Energy 45 (2), 65-69.

Neville, R.C., 1978. Solar energy collector orientation and tracking mode. Solar energy 20 (1), 7-11.

Park, K., Lee, J.H., Kim, S.H., Kwak, Y.K., 1996. Direct tracking control using time-optimal trajectories. Control Engineering Practice 4 (9), 1231-1240.

Yousef, H.A., 1999. Design and implementation of a fuzzy logic computer controlled sun tracking system. Proceedings of the IEEE International Symposium on Industrial Electronics 3, 1030-1034. 